\title{
FORCED CONVECTION COOLIG OF MULTIPLE HEAT SOURCES USING OPEN CELL METAL FOAMS
}

\author{
A. Bousri ${ }^{1 *}$, A. Hamadouche ${ }^{1}$, S. Khali ${ }^{1}$, R. Nebbali ${ }^{1}$, H. Beji ${ }^{2}$
}

\begin{abstract}
A numerical simulation is performed for heat transfer enhancement in a parallel-plate heat exchanger equipped with multiple metal foam blocks of various size. Localized heat sources are placed on the top wall of the exchanger in the location of the metallic foam blocks. The Brinkman-Forchheimer-extended Darcy model is used to characterize the flow field inside the foam region. Solution of the coupled governing equations for the composite fluid/ foam system is obtained using the finite volume method. In this study, the influence of the parameters such as the Darcy number, the Reynolds number and the arrangement of the foam samples on the hydrodynamic and thermal behavior of the flow are deeply analyzed. The results are reported for two different configurations containing four metal foam blocks mounted alternately on the top and bottom of the channel walls: (1) blocks are attached straightly to the channel walls and (2) blocks positioned at a precise distance from the channel walls. The obtained results show that the improvement of the cooling of the heat sources by forced convection is better in configuration (2).
\end{abstract}

Keywords: Numerical modeling, Heated metallic foam blocks, Laminar forced convection in the channel

\section{INTRODUCTION}

The improvement of heat exchange with a reduction of the pressure drop in the design of the heat exchangers is a major challenge. Indeed, metal foams characterized by a variable pore density, a high porosity and a good thermal conductivity allowed to improve the heat transfer in many areas such as heat exchangers, solar heating systems, cooling towers dry, cooling of electronic components ect. In heat exchangers, the effect of the metal foams parameters on heat transfer and pressure drop has been studied by several authors. Jeng et al. [1] demonstrated experimentally the heat transfer enhancement in a duct fitted with discrete aluminum foam blocks using different configurations. They used samples with uniform porosity of 0.9 and a grade of 10 PPI. They obtained 74 to $140 \%$ increase of the average Nusselt number compared to a channel without metal foam. In addition, they showed that when the blocks were placed in a staggered manner, the heat transfer was maximized while the pressure drop was minimized. Mancin et al. [2] conducted an experimental study of heat transfer and fluid flow in a horizontal channel fitted with seven aluminum open-cell foam samples of different grades, porosity and height for different air mass velocities and heat fluxes. They showed that the heat transfer coefficient increases with the air mass flow rate regardless to the heat flux value imposed. Several researchers have shown that the heat transfer performance in the partially filled channels with porous media was better than those of totally filled. So, Rong et al [3] investigated numerically the heat transfer enhancement for steady and laminar flow in the pipe partially filled with a porous medium. They showed that, when the Darcy number decreased, the temperature gradient vary quickly near the pipe wall, improved a better heat exchange efficiency. Similarly, Qu et al. [4] used numerical method to analyze the fluid flow and heat transfer in the annular duct partially filled with metal foams. Chumpia et al [5] experimentally studied forced convection in a tubular exchanger covered with different thicknesses of aluminum foam. They indicated that the heat transfer is increasing with thick foam layers. Kamath et al [6] analyzed experimentally the fluid flow and heat transfer in a duct containing symmetrically heated aluminum foams samples. Under forced convection cooling conditions using R245f refrigerant, Abadi et al [7] conducted an experimental study on the effects of metal foams pore density and mass flow rates on heat transfer and pressure loss characteristics. The results showed that as the pore density increases, heat transfer and pressure drop increase simultaneously. Further, Sung et al. [8] explored numerically how the thickness and the geometric arrangement of the porous insert relatively to the heat source in

This paper was recommended for publication in revised form by Regional Editor Alibakhsh Kasaeian

${ }^{1}$ LTPMP, Faculty of mechanical and Process engineering, Houari Boumediene university of Science and Technology, B.P. 32,

El Alia, Bab Ezzouar 16111, Algiers, Algeria

${ }^{2}$ LTI, Laboratoire de Technologie innovantes, UPJV Amiens, France

${ }^{*}$ E-mail address: bousri_a@yahoo.fr

Orcid id : 0000-0002-5021-3480, 0000-0003-3565-471X, 0000-0002-5596-3846, 0000-0001-7085-6363, 0000-0001-5437-441X

Manuscript Received 10 October 2018, Accepted 29 May 2019 
the channel augmented the heat transfer compared to the pressure drop.Wang et al. [9] used ForcheimerBrinkman equation along with the thermal equilibrium model to investigate the effect of inserting metal foams in a receiver tube installed in solar collector. The results indicated that the optimum thermo-hydraulic performance was obtained when the metal foam was inserted at the bottom of receiver tube. Chen et al [10] numerical reported forced convection in a horizontal channel using four metal-foam blocks as heat sinks. Both DarcyBrinkman-Forchheimer flow model and the two-temperature-equation model which assumes local thermal nonequilibrium (LTNE) between the fluid and the solid phases were used to characterise the thermo-flow fields inside the porous region.Yang and Hwang [11] performed numerical predictions on the heat transfer characteristics of a turbulent fluid flow in a rectangular channel fitted with porous baffles which were arranged alternately on the bottom and top channel walls. The results indicated that relatively to the solid-type baffle, the porous-type baffle presented a lower friction factor. Tajik Jamal-Abad et al [12] investigated experimentally the heat transfer enhancement in a receiver tube installed in solar parabolic collector filled with copper foam of 30 PPI. The use of the metal foam brought an improvement in Nusselt number estimated 2 times compared to tube without metallic foam. Arbak et al [13] presented pressure drop measurement for water flow in commercial open-cell aluminum foam having 10 pores per inch and a porosity of $88.5 \%$. Various flow regimes were identified. In a experimental procedure, Jeng et al [14] investigated the fluid flow and heat transfer characteristics of the aluminum foam heat sink with a conductive cylinder installed on the central position of the bottom wall of a rectangular channel with bypass spaces. Three typical bypass configurations were investigated. The aluminum-foam heat sink with a $20 \mathrm{~mm}$-diameter copper cylinder presented the highest heat transfer rates. From a previous experimental investigation, Hamadouche et al [15] demonstrated that a three metal-foams baffles of 40 PPI mounted alternatively on the top and the bottom walls of a horizontal channel create lower pressure drop and better heat transfer approximately 300\% than that obtained with an empty channel and with solid baffles. Dukhan et al [16] presented heat transfer measurement for water flow in commercial open-cell aluminum foam having 20 pores per inch and a porosity of $87.6 \%$. In summary, this bibliography research revealed that no published works addressed thermohydraulic performance of the metal foams considering less materials. Several investigations have been devoted solely to the characterization of the heat transfer in metal foams as a function of parameters, including Darcy number, porosity, Reynolds number and flow conditions. The main motivation of this numerical simulation is to explore the phenomena of interaction between the metal foam and the airflow in order to improve the thermohydraulic performance with less material in a laminar flow under a localized heat flux. To achieve intersted results, particular emphasis will be placed on the effects of various parameters governing the thermo-hydrodynamic characteristics of the airflow in the metal foams, such as Darcy's number, Reynolds number, and blocks size.

\section{MATHEMATICAL FORMULATION}

The two-dimensional flow geometry and the relevant dimensions considered in this study are schematically shown in Fig.1. The steady, laminar, and incompressible flow are adopted to investigate the forced convection heat transfer through multiple porous heated blocks in a parallel-plate channel. In addition, the following assumptions are considered:

(1) The fluid is Newtonian and its thermophysical properties are constant.

(2) The porous matrix is homogeneous, isotropic, no deformable and in local thermodynamic equilibrium with the fluid.

(3) The effective viscosity is equal to the fluid viscosity.

(4) For simplicity, the conductivity of the porous media is equal to that of the fluid in order to concentrate only in this study on the effects of geometric and thermophysical variations.

Configuration 1 :

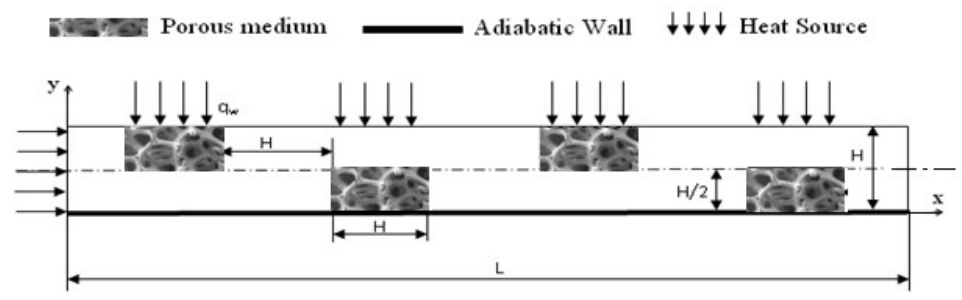


Configuration 2 :

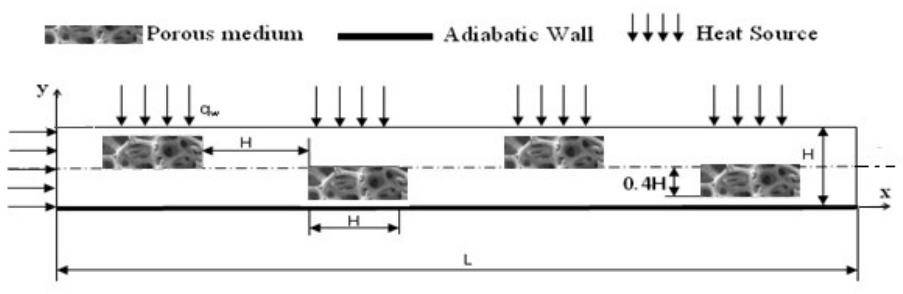

Figure 1. Schematic diagram of the problem. Configuration 1: $\mathrm{Y}_{1}=0$; Configuration 2: $\mathrm{Y}_{1}=0.1$.

To obtain the flow field, the general Darcy-Brinkman-Forchheimer model, which incorpates the inertial and viscous effects, was used in the porous blocks, while in the fluid region, the standard Navier-Stockes equations were adopted. However, to simplify the numerical procedure, one set of governing equations was used. In the fluid domain, the permeability and the porosity were taken equal to infinity and unity respectively. At the fluid/porous medium interfaces, the abrupt changes in the thermophysical properties were handled the harmonic average approach as preconized by Patankar [17]. This method has been successfully used by several authors [911]. Consequently, tacking into account the previously considered assumptions, the governing equations are as follows:

Continuity equation

$$
\frac{\partial u}{\partial x}+\frac{\partial v}{\partial y}=0
$$

Momentum equations

$$
\begin{aligned}
& \frac{\rho}{\varepsilon^{2}}\left[u \frac{\partial u}{\partial x}+v \frac{\partial u}{\partial y}\right]=-\frac{\partial p}{\partial x}-\frac{\mu}{K} u-\frac{\rho C_{F}}{\sqrt{K}} \sqrt{u^{2}+v^{2}} u+\mu_{e}\left[\frac{\partial^{2} u}{\partial x^{2}}+\frac{\partial^{2} u}{\partial y^{2}}\right] \\
& \frac{\rho}{\varepsilon^{2}}\left[u \frac{\partial v}{\partial x}+v \frac{\partial v}{\partial y}\right]=-\frac{\partial p}{\partial y}-\frac{\mu}{K} v-\frac{\rho C_{F}}{\sqrt{K}} \sqrt{u^{2}+v^{2}} v+\mu_{e}\left[\frac{\partial^{2} v}{\partial x^{2}}+\frac{\partial^{2} v}{\partial y^{2}}\right]
\end{aligned}
$$

Energy equation

$$
\rho c_{p}\left(u \frac{\partial T}{\partial x}+v \frac{\partial T}{\partial y}\right)=k_{e}\left(\frac{\partial^{2} T}{\partial x^{2}}+\frac{\partial^{2} T}{\partial y^{2}}\right)
$$

The non-slip boundary condition is considered at the impermeable walls which are insulated except at the porous block emplacement where a uniform heat flux is applied. The fluid at the channel inlet enters into the domain with both uniform velocity and temperature.

To prevent the entrance effects, the computational domain is extended 5 times the channel height upstream the porous blocks location. Similarly, the downstream channel length is assumed to be sufficiently long so that fully developed boundary conditions can be applicable at the exit. Therefore, the relevant boundary conditions that complement the mathematical model are summarized as follows:

Inlet: $\mathrm{x}=0$

$$
u(0, y)=U_{0}, \quad v(0, y)=0, T(0, y)=T_{0}
$$

Top wall: $\mathrm{y}=\mathrm{H}$

$$
u(x, H)=v(x, H)=0,\left.\quad k_{f} \frac{\partial T}{\partial y}\right|_{y=H}=\alpha q_{w}
$$


Bottom wall: $\mathrm{y}=0$

$$
u(x, 0)=v(x, 0)=0,\left.\quad \frac{\partial T}{\partial y}\right|_{y=0}=0
$$

Outlet: $\mathrm{x}=\mathrm{L}$

$$
\frac{\partial u}{\partial x}=0, v=0, \quad \frac{\partial T}{\partial x}=0
$$

The variable $\alpha$ takes the value 1 in the heated regions. Elsewhere, it is set to zero. The governing equations are cast into dimensionless form by introducing the following non-dimensional variables:

$$
X=\frac{x}{H} ; Y=\frac{y}{H} ; U=\frac{u}{U_{0}} ; V=\frac{v}{U_{0}} ; P=\frac{p}{\rho U_{0}^{2}} ; \text { and } \theta=\frac{T-T_{0}}{\left(q_{w} H\right) / k_{f}}
$$

Continuity equation

$$
\frac{\partial U}{\partial X}+\frac{\partial V}{\partial Y}=0
$$

Momentum equations

$$
\begin{aligned}
& U \frac{\partial U}{\partial X}+V \frac{\partial U}{\partial Y}=-\left(\left(1-\varepsilon^{-2}\right) \lambda+\varepsilon^{-2}\right) \frac{\partial P}{\partial X}-\lambda \varepsilon^{2}\left[\frac{1}{R e D a}+\frac{C_{F}|\vec{V}|}{\sqrt{D a}}\right] U+(\lambda(\varepsilon-1)+1) \frac{R_{\mu}}{R e}\left[\frac{\partial^{2} U}{\partial X^{2}}+\frac{\partial^{2} U}{\partial Y^{2}}\right] \\
& U \frac{\partial V}{\partial X}+V \frac{\partial V}{\partial Y}=-\left(\left(1-\varepsilon^{-2}\right) \lambda+\varepsilon^{-2}\right) \frac{\partial P}{\partial Y}-\lambda \varepsilon^{2}\left[\frac{1}{R e D a}+\frac{C_{F}|\vec{V}|}{\sqrt{D a}}\right] V+(\lambda(\varepsilon-1)+1) \frac{R_{\mu}}{R e}\left[\frac{\partial^{2} V}{\partial X^{2}}+\frac{\partial^{2} V}{\partial Y^{2}}\right]
\end{aligned}
$$

Energy equation

$$
U \frac{\partial \theta}{\partial X}+V \frac{\partial \theta}{\partial Y}=\frac{\lambda\left(R_{k}-1\right)+1}{R e P r}\left(\frac{\partial^{2} \theta}{\partial X^{2}}+\frac{\partial^{2} \theta}{\partial Y^{2}}\right)
$$

The dimensionless boundary conditions are as follows:

Inlet:

$$
U(0, Y)=1, \quad V(0, Y)=0, \quad \theta(0, Y)=0
$$

Top wall:

$$
U(X, 1)=V(X, 1)=0,\left.\quad \frac{\partial \theta}{\partial Y}\right|_{Y=1}=\alpha
$$

Bottom wall:

$$
U(X, 0)=V(X, 0)=0,\left.\quad \frac{\partial \theta}{\partial Y}\right|_{Y=0}=0
$$

Outlet:

$$
\frac{\partial U}{\partial X}=0, V=0, \quad \frac{\partial \theta}{\partial X}=0
$$


The dimensionless parameters appearing in the above equations are defined as:

$$
R e=\frac{U_{0} H}{\gamma} ; D a=\frac{K}{H^{2}} ; R_{k}=\frac{k_{e}}{k_{f}} ; R_{\mu}=\frac{\mu_{e}}{\mu_{f}} ; \operatorname{Pr}=\frac{\mu C_{p}}{k_{f}} \text { and } C_{F}=\varepsilon F
$$

\section{Governing Parameters}

The local friction coefficient is defined as:

$$
f=\frac{\left(-\frac{d p}{d x}\right) D_{h}}{2 \rho U_{0}^{2}}
$$

Thereafter, to point out how the porous blocks impact the heat transfer, the local Nusselt number along the heated surfaces is defined as:

$$
N u_{x}=\frac{h_{x} H}{k_{f}}
$$

While the average Nusselt number over the emplacement of the porous blocks is calculated as follow:

$$
N u_{i}=\frac{1}{w_{i}} \int N u_{x} d x
$$

The global average Nusselt number is given by:

$$
N u_{m}=\frac{1}{N} \sum N u_{i}
$$

Using the dimensionless variables, the last two parameters are written as:

$$
\begin{gathered}
f=\left(-\frac{d P}{d X}\right) \\
N u_{X}=\frac{\left.\left[\left(R_{k}-1\right) \lambda+1\right] \frac{\partial \theta}{\partial Y}\right|_{Y=1}}{\theta_{w}-\theta_{b}(x)}
\end{gathered}
$$

The mean bulk temperature $\theta_{\mathrm{b}}$ is obtained using the dimensionless expression:

$$
\theta_{b}=\frac{\iint U \theta d X d Y}{\iint U d X d Y}
$$

\section{Numerical Procedure}

The governing equations were solved numerically by using the SIMPLE algorithm along with the TDMA algorithm to link the pressure and velocity fields as reported in [17]. It is based on the finite volume method, which ensures conservation of mass, momentum and energy on each control volume as well as across the fluid/porous interface. The interaction between the convection and diffusion terms were handled with the power law scheme. As aforementioned, based on the suggestions of Patankar [17], the harmonic mean formulation is used to prevent the effects of abrupt change of the thermophysical properties at the different interfaces of the domain. A non uniform grid system with a large concentration of nodes in regions of steep gradients, such as those close to the channel walls and fluid/porous blocks interfaces, was employed. To analyze the effect of the grid size on the numerical solution, various grid systems were tested. A grid system of 80 x 220 (in Y and X directions respectively) was chosen, it ensures a good accuracy while maintaining the calculation time at acceptable levels. For the convergence criteria that ends the iterative process, it was considered that relative 
variations of the velocity components and temperature between two successive iterations less than $10^{-6}$ were sufficient.

\section{Code Validation}

We checked the accuracy and validity of the developed numerical procedure by performing comparisons with already published results. Firstly, Fig.2 shows the flow pattern we compared with that of Sung et al. [8] in the cases of a single porous block occupying $50 \%$ and $90 \%$ of the channel height for $\mathrm{Da}=10^{-5}$ and $\mathrm{Re}=100$. As it can be seen, our results agree well with that of the reference.

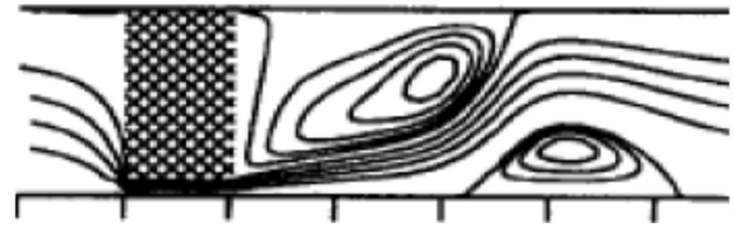

a1: Sung et al [8]

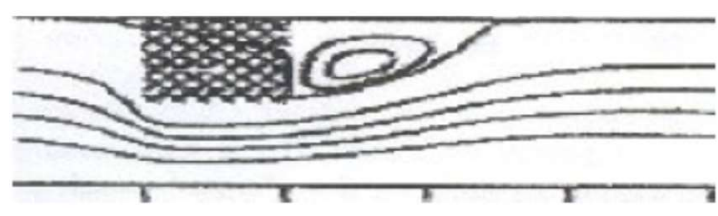

b1: Sung et al [8]

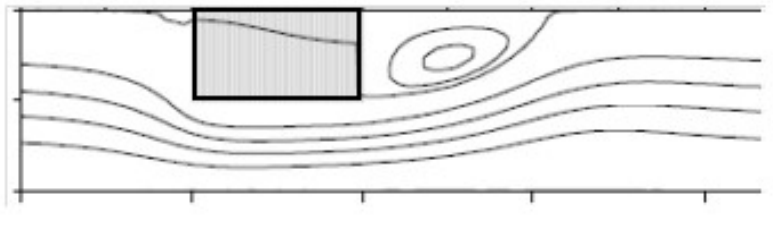

a2: Present work

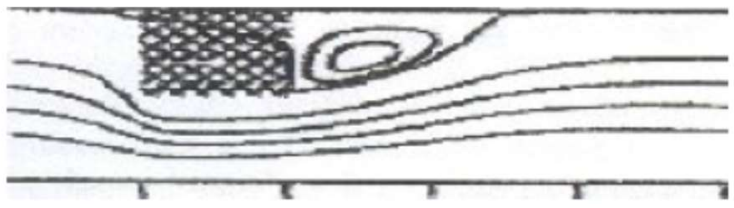

b2: Present work

Figure 2. Comparison of the streamlines contours with that obtained by Sung et al. [8], with permission from Elsevier. (a) $\mathrm{Re}=100, \mathrm{Da}=10^{-5}, \mathrm{~S}=0.9$ and (b) $\mathrm{Re}=100, \mathrm{Da}=10^{-5}, \mathrm{~S}=0.5$.

Secondly, we have portrayed in Fig.3, the obtained local wall temperature $\boldsymbol{\theta}_{\mathrm{p}}$, with that of Sung et al. [8]. We notice a good agreement between the two studies.

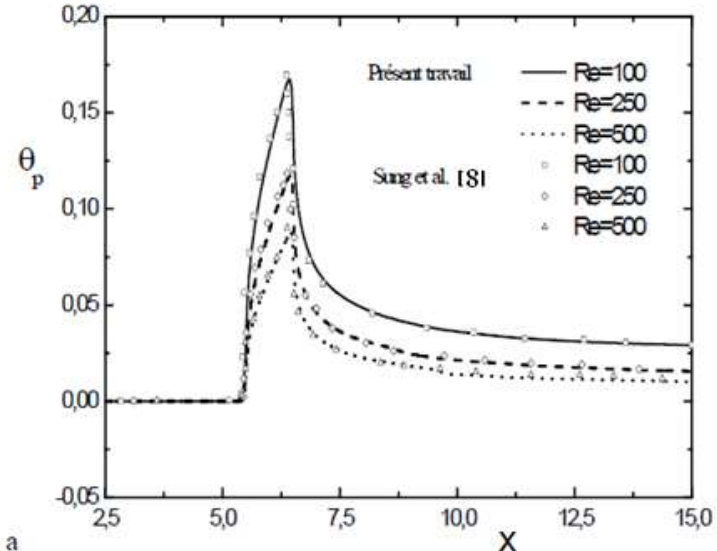

(a)

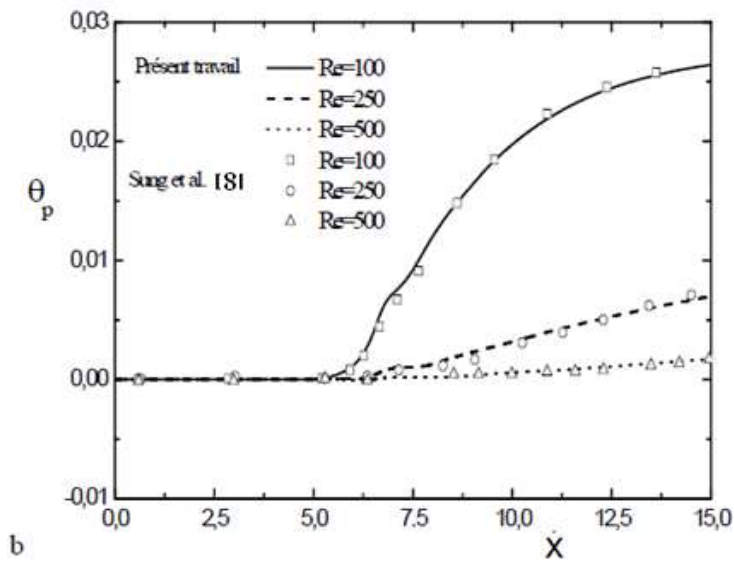

(b)

Figure 3. Comparison of the local temperatures, (a) Bottom wall, (b) Top wall, with that obtained by Sung et al. [8], with permission from Elsevier. For $\mathrm{Da}=10^{-5}, \mathrm{~S}=0.5$ and $\mathrm{R}_{\mathrm{k}}=1$.

However, in order to accuracy of the present numerical scheme, others comparisons with other literatures are necessary. A comparison was made with the results obtained by Chen et al [10]. These researchers performed a numerical study of the airflow and heat transfer throught a multiple aluminium foam heat sink inserted in a horizontal channel as shown in Fig.4. 


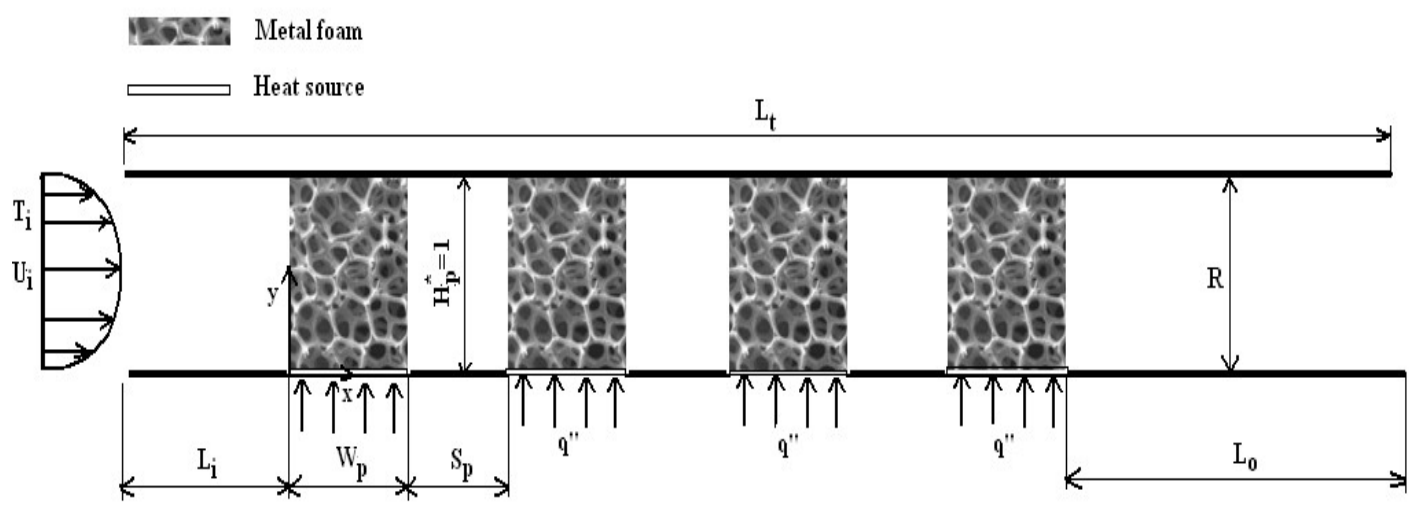

Figure 4. Schematic diagram of the problem studied by Chen et al [10], with permission from Elsevier. For $\left(\mathrm{R}=20 \mathrm{~mm}, H_{p}^{*}=1, W_{p}^{*}=1, \mathrm{~S}_{\mathrm{p}}^{*}=1, \varepsilon=0.95, \mathrm{~K}=1.6510^{-7} \mathrm{~m}^{2}, F=0.099\right)$

The flow is modeled by the Darcy-Brinkman-Forchheimer equations in the porous matrix to incorporate the viscous and inertial effects, and by the Navier-Stokes equations in the fluid domain. The mathematical model for energy transport is based on the two-temperature-equation model which assumes local thermal nonequilibrium (LTNE) between the fluid and the solid phases. The results are in good agreement with the numerical results reported by the authors for the local temperature distribution in the case without metal foam, while in the case with metal foam, the results are totally different and this is due, to the mathematical model for energy transport taken by the authors, as shown in Fig.5. This validation demonstrates the ability of the computer code to handle problems with coexisting open and porous regions.

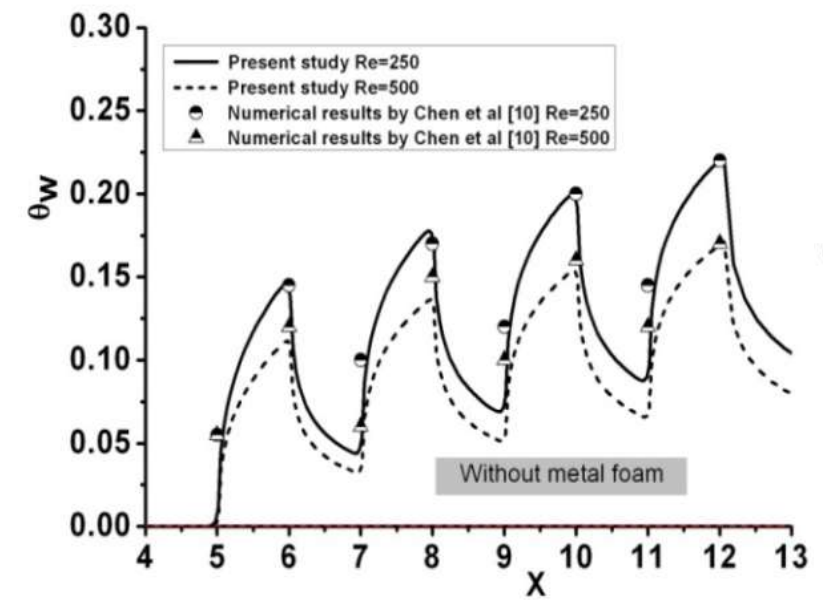

(a)

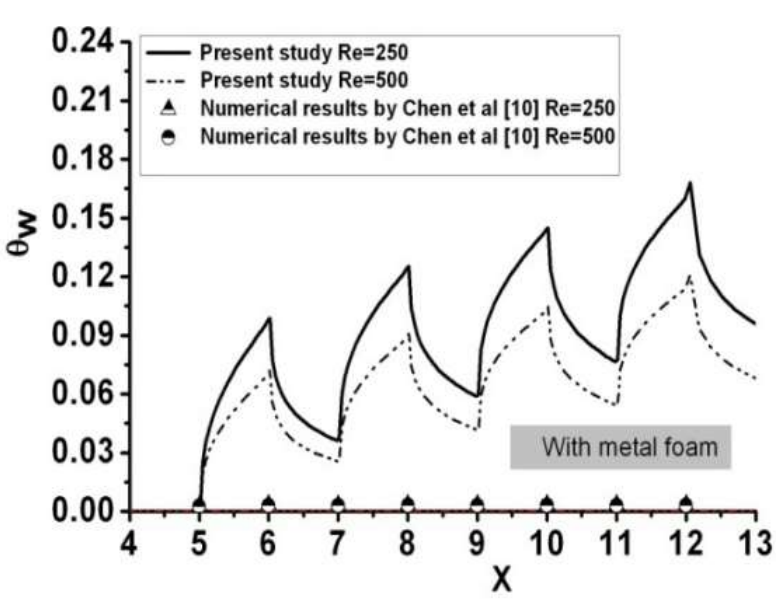

(b)

Figure 5. The results compared with other literatures. (a) Local temperature distribution along the bottom wall without metal foam obtained by Chen et al [10], with permission from Elsevier. (b) Local temperature distribution along the bottom wall with metal foam obtained by Chen et al [10], with permission from Elsevier.

\section{RESULTS AND DISCUSSIONS}

To investigate the Darcy number effect on the flow and temperature fields, computations were carried out for $\mathrm{Re}=150$ and $\mathrm{Da}$ ranging from $10^{-6}$ to 1 . The latter value corresponds to the non porous case. Table 1 gives the characteristics of certain porous materials as the permeability and its corresponding Darcy number, Forchheimer coefficient, porosity and the channel height. It is noticed that the aluminum metal foam exhibits the lowest Darcy number. 
Table 1. Permeability and Forchheimer coefficients in various flow regimes for three porous media

\begin{tabular}{|c|c|c|c|c|c|c|}
\hline Porous media & $\varepsilon$ & $\begin{array}{c}\text { Flow } \\
\text { regime }\end{array}$ & $\begin{array}{c}\mathbf{K x 1 0}{ }^{9} \\
\left(\mathbf{m}^{2}\right)\end{array}$ & $\mathbf{F}$ & $\begin{array}{c}\mathbf{H} \\
(\mathbf{m m})\end{array}$ & Da \\
\hline $\begin{array}{c}\text { Packed spheres } \\
1 \mathrm{~mm}\end{array}$ & 0.350 & $\begin{array}{c}\text { Darcy } \\
\text { Forchheimer } \\
\text { Turbulent }\end{array}$ & $\begin{array}{l}0.69 \\
1.00 \\
\text { NA }\end{array}$ & $\begin{array}{c}\text { NA } \\
0.54 \\
\text { NA }\end{array}$ & 20 & $\begin{array}{l}1.710^{-6} \\
2.510^{-6}\end{array}$ \\
\hline $\begin{array}{c}\text { Packed spheres } \\
\text { 3mm }\end{array}$ & 0.355 & $\begin{array}{c}\text { Darcy } \\
\text { Forchheimer } \\
\text { Turbulent }\end{array}$ & $\begin{array}{l}6.18 \\
7.34 \\
6.61\end{array}$ & $\begin{array}{l}\text { NA } \\
0.43 \\
0.39\end{array}$ & 20 & $\begin{array}{l}1.510^{-5} \\
1.810^{-5} \\
1.610^{-5}\end{array}$ \\
\hline $\begin{array}{l}\text { Metal foam } 20 \\
\text { PPI } \\
\text { Aluminum alloy }\end{array}$ & 0.876 & $\begin{array}{c}\text { Darcy } \\
\text { Forchheimer } \\
\text { Turbulent }\end{array}$ & $\begin{array}{c}67.7 \\
52.9 \\
347.2\end{array}$ & $\begin{array}{l}\text { NA } \\
5.29 \\
0.112\end{array}$ & 20 & $\begin{array}{l}1.610^{-4} \\
1.310^{-4} \\
8.610^{-4}\end{array}$ \\
\hline
\end{tabular}

This section provides an overview of the obtained results while showing the combined effects of the Darcy and Reynolds numbers and the porous blocks arrangement in the channel on both hydrodynamic and thermal behavior of the flow. The first simulations were conducted without a gap. Fig.6, where streamlines and isotherms are portrayed for the configuration $1\left(\mathrm{Y}_{1}=0\right)$, shows how the flow structure is affected by the presence of the porous blocks. Thus, the streamlines present important distortions in the channel. Indeed, it is noticed the appearrence of a weak recirculation forward and a vortex backward each block. The intensity and extent of these vortices are strongly affected by the permeability. For $\mathrm{Da}=10^{-6}$ (Fig.6e), most of the flow crosses the free passage between the channels walls and the porous blocks such that there is no fluid penetration in these blocks which behave, then, as solid blocks. As the permeability increases the resistance to the flow opposed by the blocks diminishes, and, therefore, more and more flow passes through the porous blocks. As a consequence, around $\mathrm{Da}=10^{-2}$ (Fig.6b), the vortices disappear completely and the flow recovers nearly the structure observed for a channel without porous blocks, as it can observed in Fig.6a.

The Darcy number plays also a significant role in affecting the temperature field. The thermal boundary layer thickness increases at high Da and becomes distorted when the fluid has difficulty penetrating the porous block as shown in Fig.6i and Fig.6j.

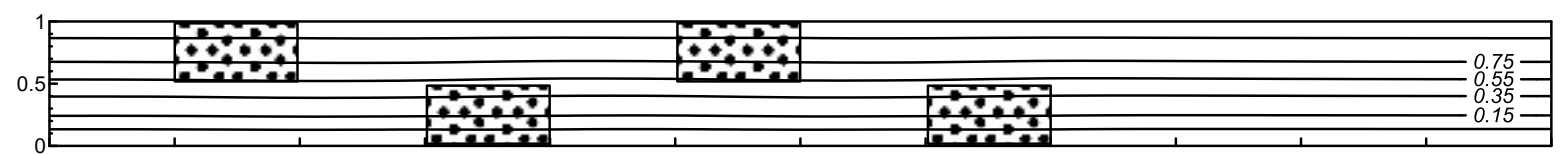

(a)

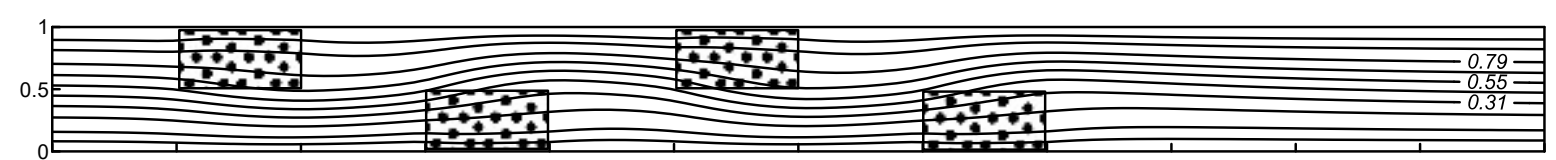

(b)

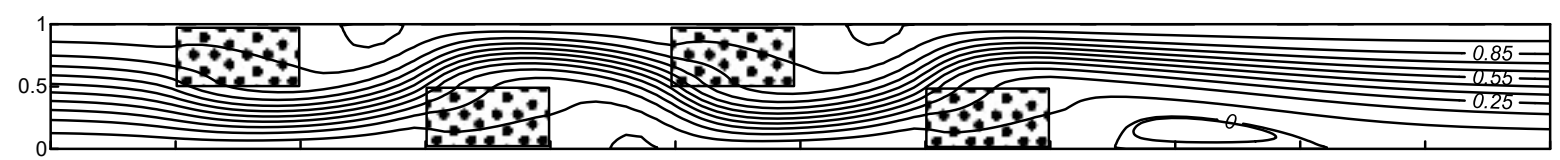

(c)

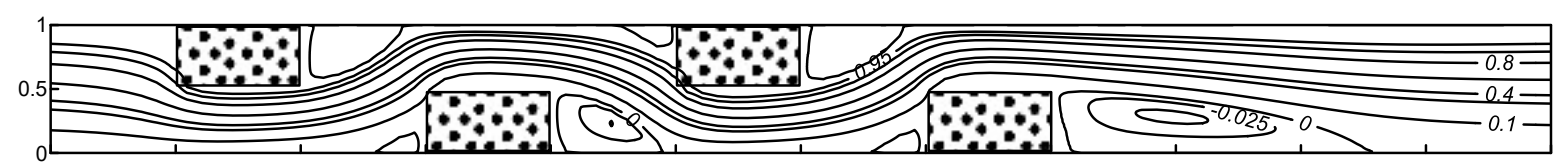

(d) 


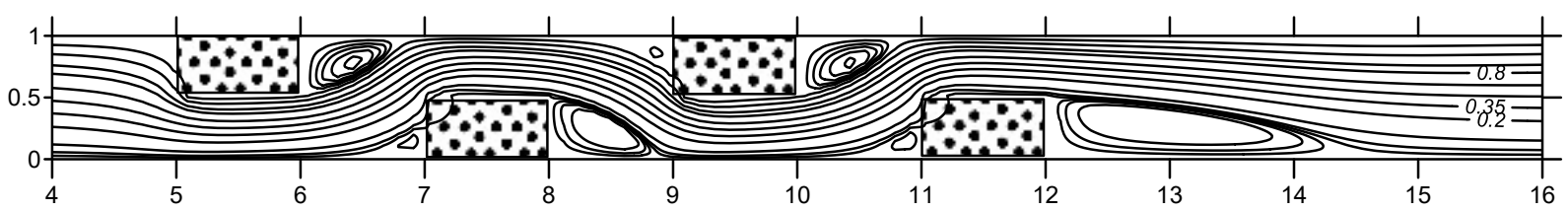

(e)

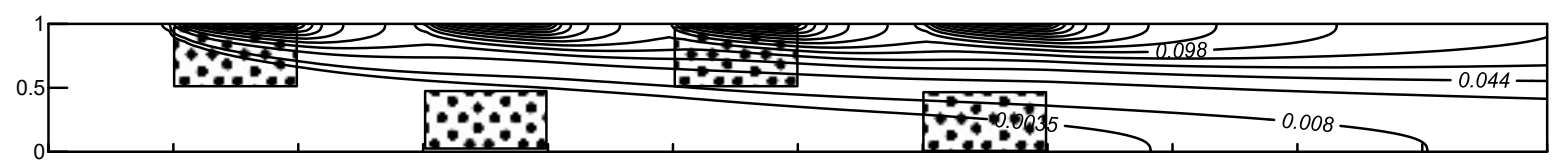

(f)

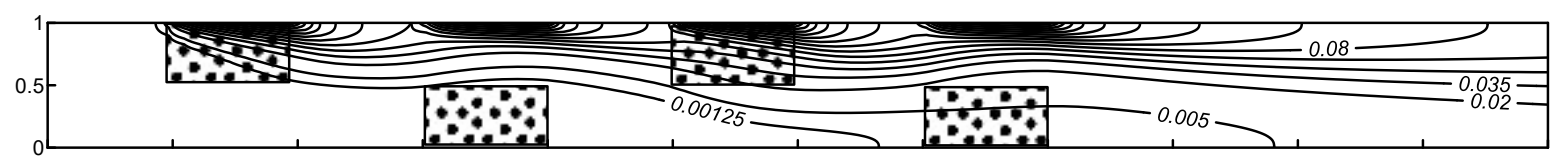

(g)

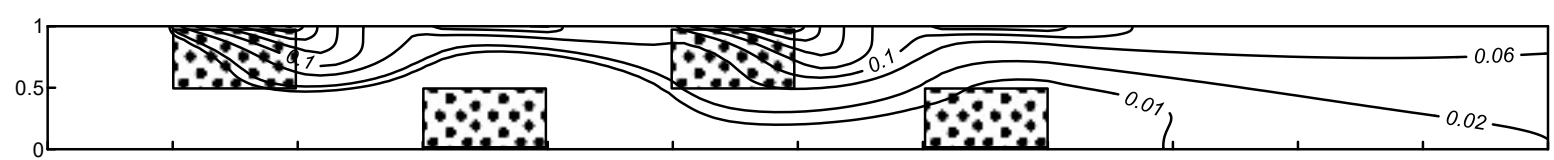

(h)

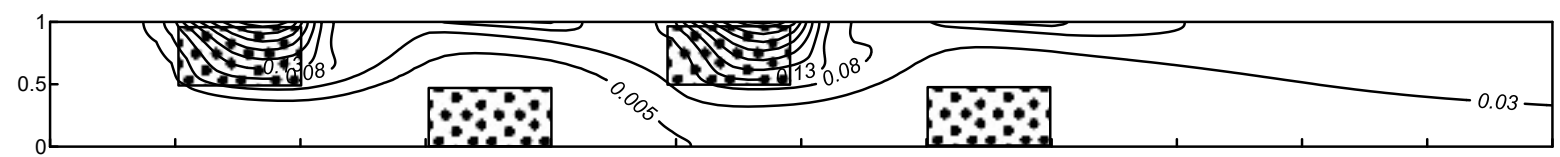

(i)

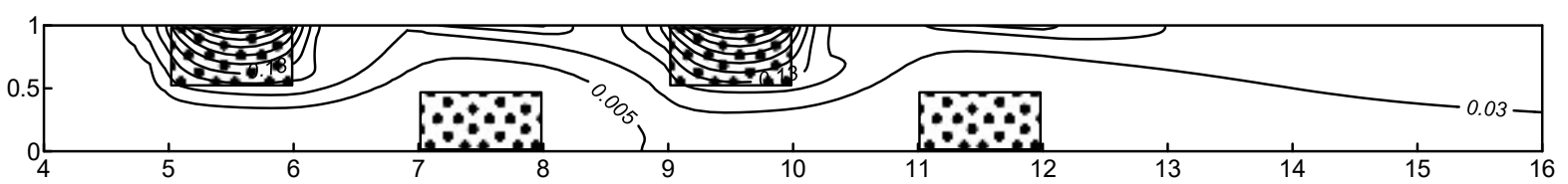

(j)

Figure 6. Evolution of the streamline and isotherm for: $\mathrm{Y}_{1}=0, \mathrm{Re}=150$, (a) $\mathrm{Da}=1$; (b) $\mathrm{Da}=10^{-2}$; (c) $\mathrm{Da}=10^{-3}$; (d) $\mathrm{Da}=10^{-4}$; (e) $\mathrm{Da}=10^{-6}$; (f) $\mathrm{Da}=1 ;$ (g) $\mathrm{Da}=10^{-2}$; (h) $\mathrm{Da}=10^{-3}$; (i) $\mathrm{Da}=10^{-4}$; (j) $\mathrm{Da}=10^{-6}$.

The second simulation were conducted with gap. Fig.7 shows the evolution of the streamlines for the second configuration $\left(\mathrm{Y}_{1}=0.1\right)$ where a gap between the channel walls and blocks was created. From a phenomenological point of view, overall the features and trends are observed. However, we noticed some interesting features and trends. First, some fluid passes trough the gap even for low permeability (Fig.7e), and this will probably improve the wall cooling. Second, the fluid leaving the narrow gap as a jet drives the vortices, backward the blocks, to the right while lowering their intensities, and eventually vanishes for $\mathrm{Da}=10^{-3}$ (Fig.7c).

Third, we noticed also that the fluid penetration is better (Fig.7b) which can also have a positive impact on the heat transfer. The narrow gaps close to the channel wall affect also the temperature field as it is noticed in Fig. $7 \mathrm{~h}$. Consequently, the open regions created by the porous blocks and their corresponding wall, affect seriously the temperature field in the walls as shown in Fig.7i and $7 \mathrm{j}$. The thermal boundary layer thickness increases at high Darcy number and becomes distorted when the fluid has difficulty to leaving the gap.

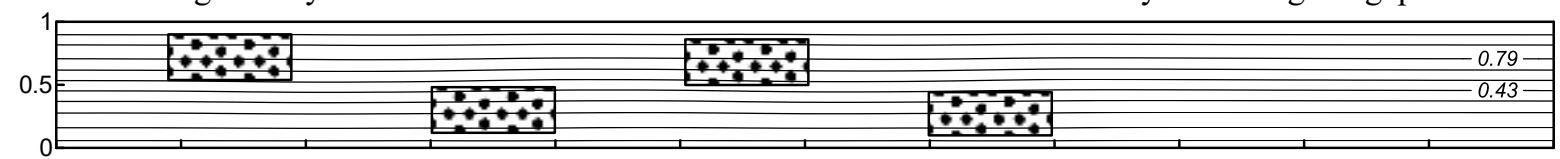

(a)

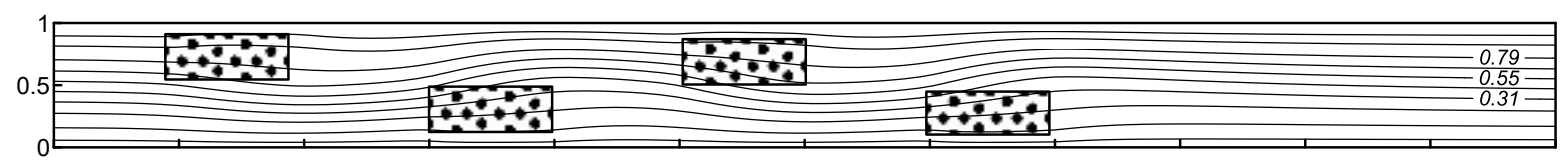

(b) 


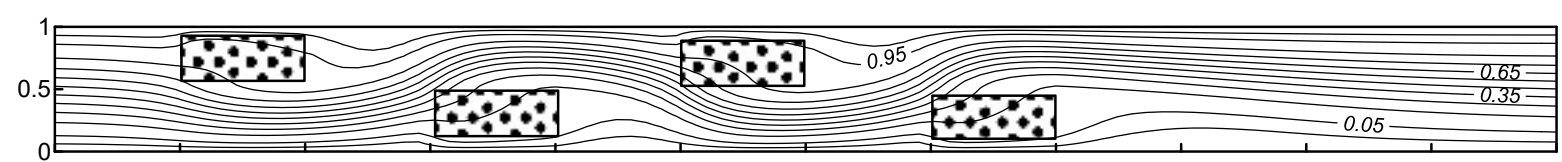

(c)

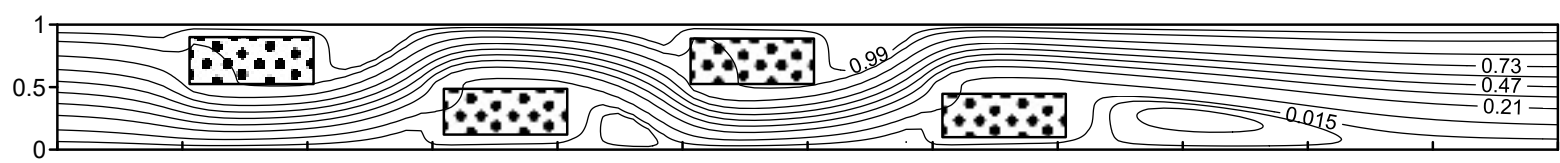

(d)

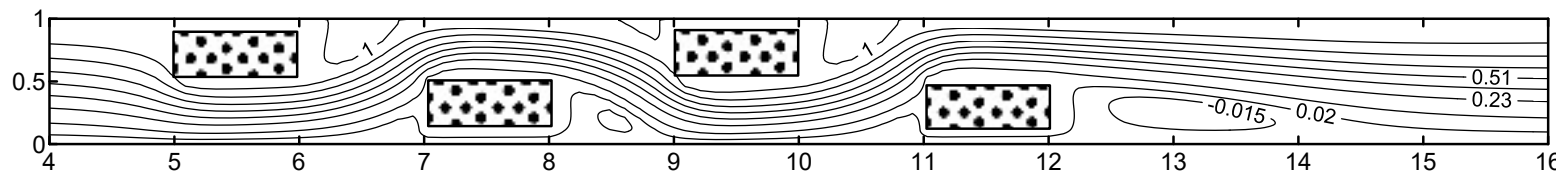

(e)

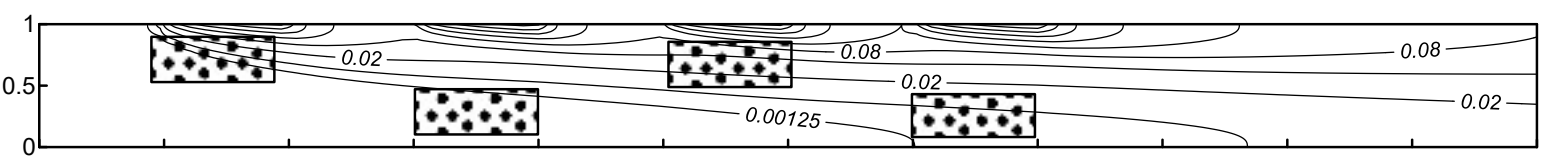

(f)

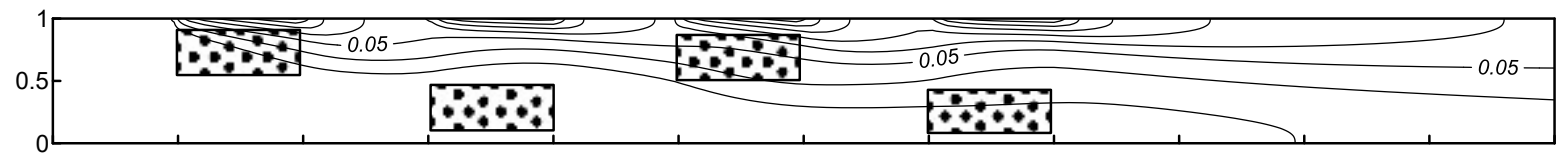

(g)

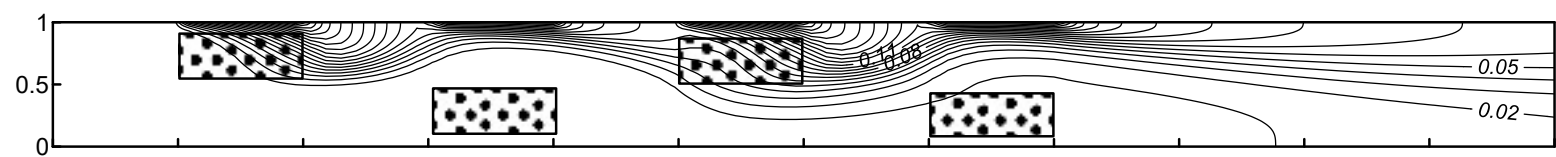

(h)

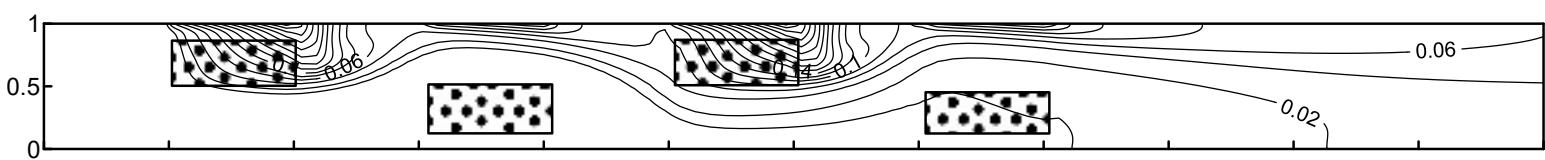

(i)

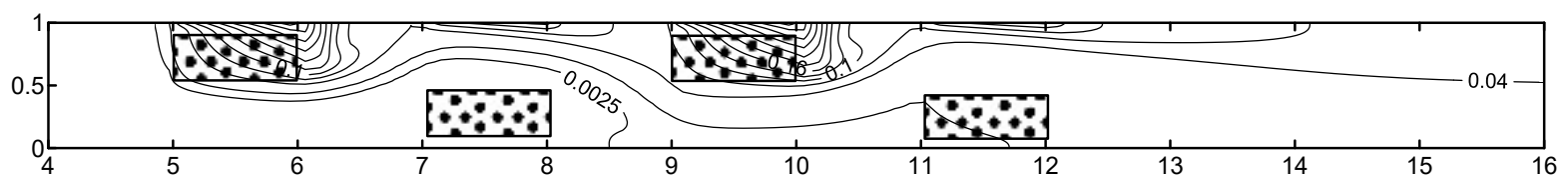

(j)

Figure 7. Evolution of the streamline and isotherm for: $\mathrm{Y}_{1}=0.1, \mathrm{Re}=150$, (a) $\mathrm{Da}=1$; (b) $\mathrm{Da}=10^{-2}$; (c) $\mathrm{Da}=10^{-3}$; (d) $\mathrm{Da}=10^{-4}$; (e) $\mathrm{Da}=10^{-6}$; (f) $\mathrm{Da}=1 ;$ (g) $\mathrm{Da}=10^{-2}$; (h) $\mathrm{Da}=10^{-3}$; (i) $\mathrm{Da}=10^{-4}$; (j) $\mathrm{Da}=10^{-6}$.

The layout of the porous blocks makes the fluid path tortuous in the channel and altercates the velocity field. This is well illustrated in Fig.8a for the configuration $1\left(\mathrm{Y}_{1}=0\right)$, which shows the stream-wise velocity profiles at the middle of each of the porous blocks for different Darcy numbers and $\mathrm{Re}=150$. It reveals that the flow is strengthened in the non-porous region as the permeability decreases intensifying the convective effect close to the walls. On the other hand, in the porous substrates the opposite effect is observed characterized with a weak flow. The effect of variation of the Reynolds number on the velocity field for $\mathrm{Da}=10^{-6}$ is depicted in Fig. 8 b. One can notice, for such permeability, that increasing the Reynolds number from 50 to 250 has nearly no effect on the velocity, and the porous blocks almost act as solids. In addition, it will increase the pressure drop. 

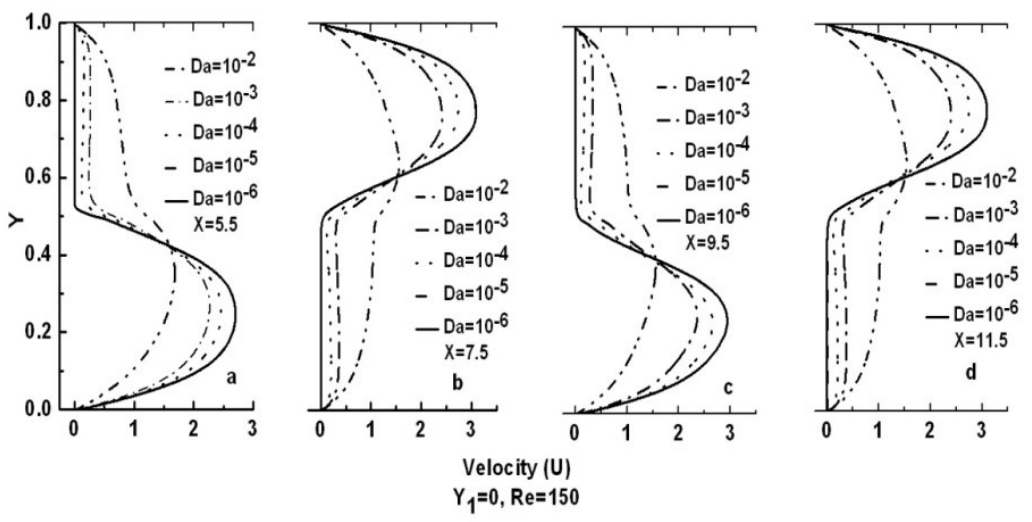

(a)
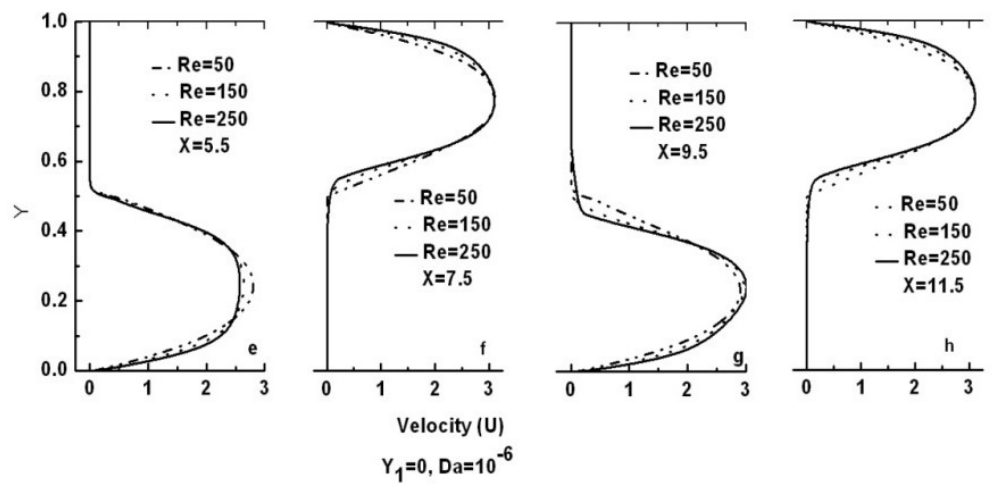

(b)

Figure 8. Effects of Darcy and Reynolds numbers on the velocity for: $\mathrm{Y}_{1}=0$.

The same velocity profiles for the configuration $2\left(\mathrm{Y}_{1}=0.1\right)$ are shown in Fig.9. The effect of the Darcy number on the velocity field for $\mathrm{Re}=150$ are analyzed. As it can be seen, some quantity of fluid crosses the narrow passages which will probably help heat dissipation. One can notice, that the flow is fastest in that regions. But in the large gaps, the highest velocity is observed for $\mathrm{Da}=10^{-4}$ and $10^{-6}$ where both profiles merge practically into one. Comparing the two cases, it is noticed that the inserted gaps do not affect signifanctly the core flow.
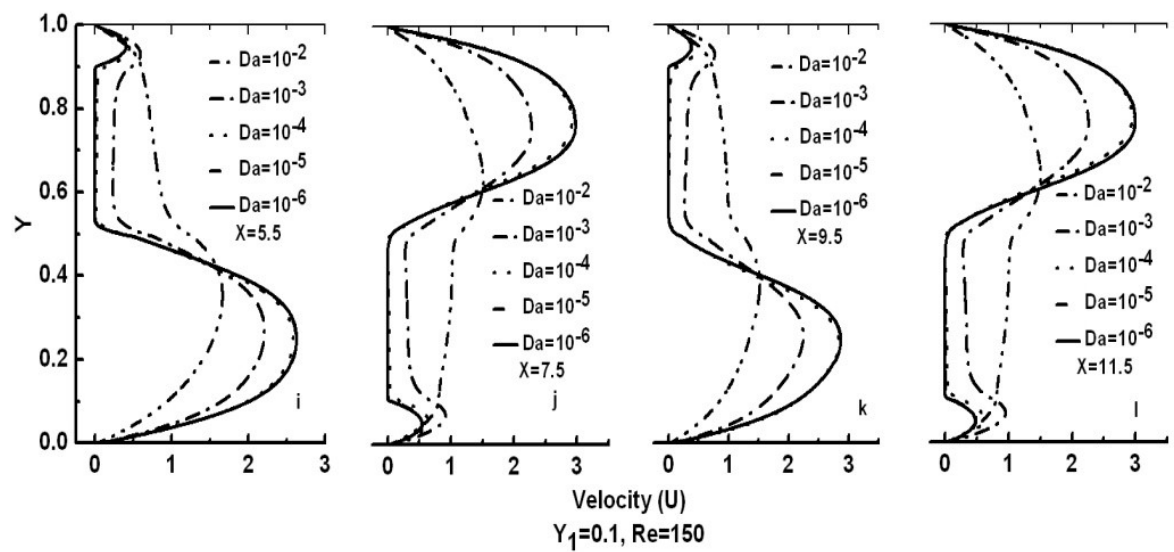

Figure 9. Effects of Darcy number on the velocity for: $\mathrm{Y}_{1}=0.1$.

Temperature surfaces for security reasons should be maintained at specific values. The effect of Darcy number on the top wall local temperature for the both configurations for $\mathrm{Re}=150$ is shown in Fig.10. As expected, in the first and third blocks the wall temperature increases as the permeability decreases. For $\mathrm{Da}=10^{-4}$ 
and $10^{-6}$, the maximum temperature is approximately 2.5 times higher than that of the non porous channel for configuration I (Fig.10a). For configuration II, this value drops around 1.5 as shown in Fig.10b. On the regions of the second and fourth block, we observe the opposite effect. In these locations, the flow is intensified close to the heat wall because of the reduction of the section. Therfore, the heat dissipation is improved. For $\mathrm{Da}=10^{-4}$ and $10^{-6}$, the minimum temperature is approximately around 1.6 times lower than that of the non porous channel for the both configurations. The behavior observed in the evolution of the wall temperature is due to the fact that the flow resistance due to the porous blocks diminishes as the permeability increases. This allow more fluid penetration in the blocks.

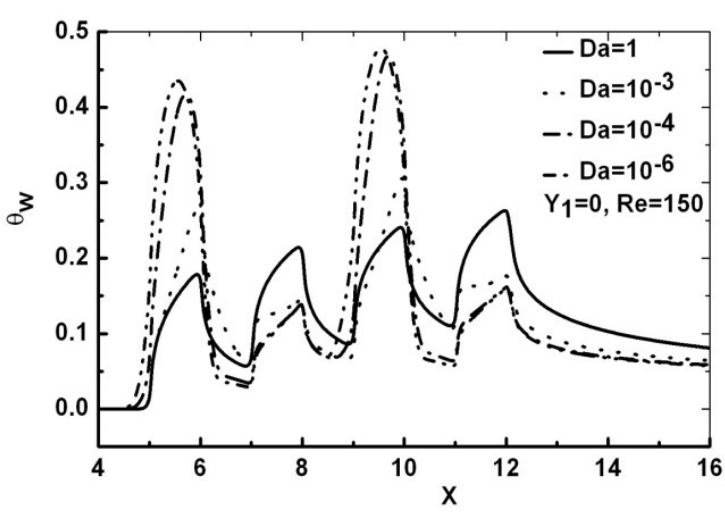

(a)

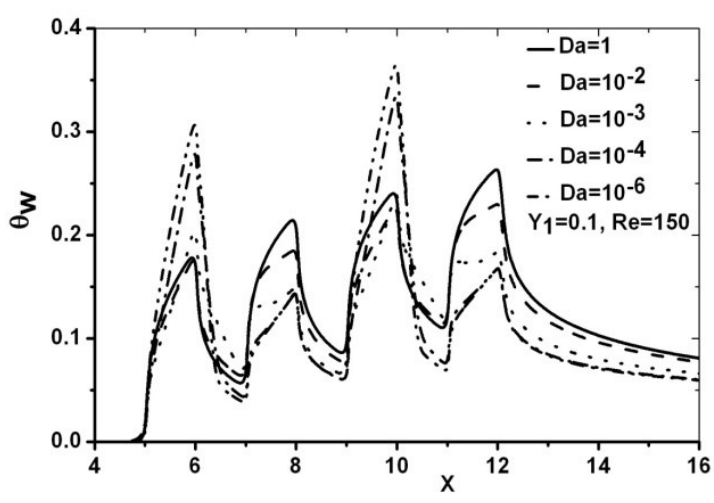

(b)

Figure 10. Effects of Da on the top wall temperature distribution for: (a) $\mathrm{Y}_{1}=0$; (b) $\mathrm{Y}_{1}=0.1$.

We show now, the effects of Reynolds number on the wall temperature for configuration 1 and 2 ( $Y_{1}=0$ and $\mathrm{Y}_{1}=0.1$ ) for $\mathrm{Da}=10^{-3}$, as shown in Fig. 11a and $11 \mathrm{~b}$. At lowest Reynolds number $\mathrm{Re}=50$, the maximum wall temperature is obtained for the both configurations. When the Reynolds number is increased, the fluid is forced to flow through the porous blocks and hence can dissipate the heat from the heating wall and decrease consequently the wall temperature. Eventually, it should be noted that the wall temperature decrease significantly by creating the gaps between the porous block and the heated source specially when the Reynolds number increases as seen in Fig.11b.

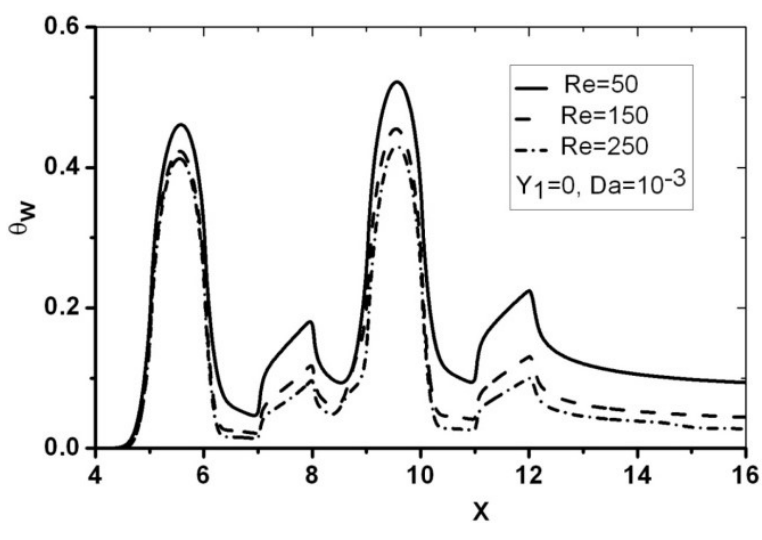

(a)

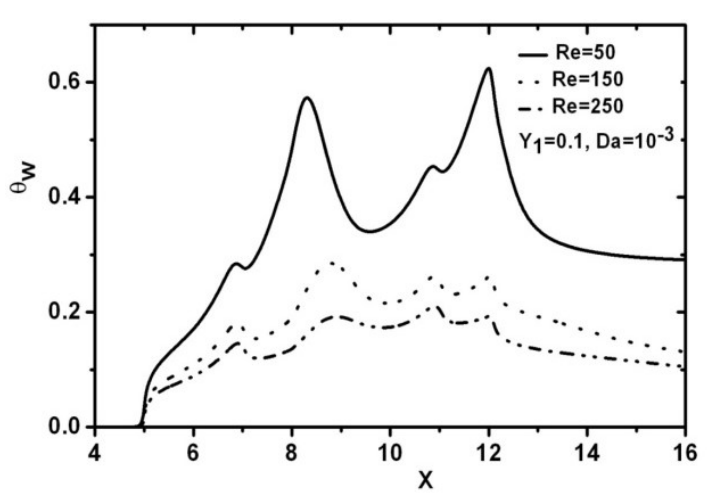

(b)

Figure 11. Effects of Re on the top wall temperature distribution for: (a) $\mathrm{Y}_{1}=0$, (b) $\mathrm{Y}_{1}=0.1$.

The relationship between the local Nusselt number and the Darcy number at the top wall for configuration $1\left(\mathrm{Y}_{1}=0\right)$ for $\mathrm{Re}=150$ is shown in Fig.12. One can see that the local Nusselt number Nux is significantly affected by the air path guided by the porous blocks and a significant enhancement in heat transfer occurs when Da passes from 1 to $10^{-6}$. Consequently, a large increase in $\mathrm{Nu}_{\mathrm{x}}$ corresponding to the second and last porous block is observed for $\mathrm{Da}$ egal to $10^{-4}$ and $10^{-6}$, this is explained by the large amount of fluid flowing through the free space created by the second porous block which significantly enhances heat transfer by convection. The 
lowest $\mathrm{Nu}_{\mathrm{x}}$ is observed at the third porous block for a lower $\mathrm{Da}\left(\mathrm{Da}=10^{-6}\right)$ because the fluid has difficulty penetrating through the porous block which decreases the heat transfer.

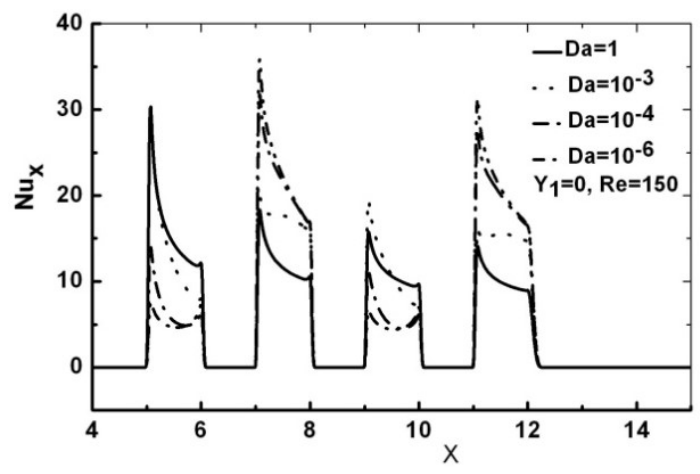

Figure 12. Effects of Da on the local Nusselt evolution for $\mathrm{Y}_{1}=0$.

On the other hand,for configuration $2\left(\mathrm{Y}_{1}=0.1\right)$ at $\mathrm{Re}=150$, the variation of local Nusselt number for various Darcy numbers is shown in Fig.13. Comparatively to configuration 1, Nux is significantly affected by the air jet flowing throught the gaps so a large improvement in heat transfer at the third porous block is observed at a lower Darcy number $\left(\mathrm{Da}=10^{-6}\right)$.

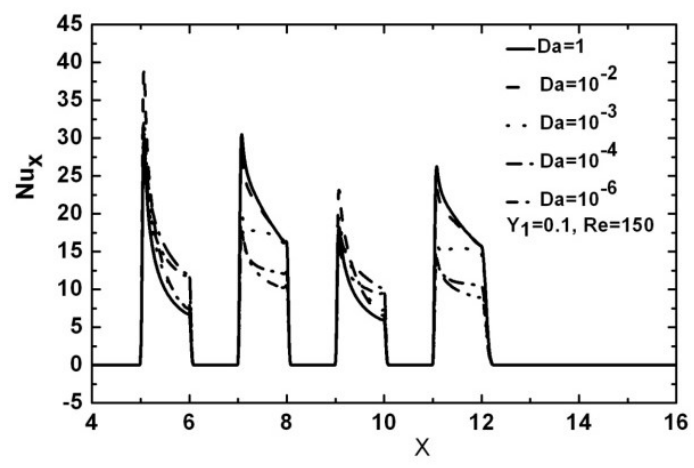

Figure 13. Effects of Da on the local Nusselt evolution for $\mathrm{Y}_{1}=0,1$.

The average Nusselt number $\mathrm{Nu}_{\mathrm{m}}$ based on the Darcy number for the two configurations studied previously is shown in Fig.14. The result demonstrates that the configuration $2\left(\mathrm{Y}_{1}=0.1\right)$ present $\mathrm{Nu}_{\mathrm{m}}$ much interest around $12 \%$ that the configuration $1\left(\mathrm{Y}_{1}=0\right)$ for the Darcy number lower then $10^{-3}$. In fact when the porous blocks are decollated from the wall $\left(\mathrm{Y}_{1}=0.1\right)$ and their permeability is lowed, the fluid well be forced to accelerate in the narrow gap, which increases the velocity gradient and therefore the convective heat transfer on the walls. Another interesting result shows that the maximum Num occurs for a Darcy number equal to $10^{-3}$ corresponding to metal foam material.

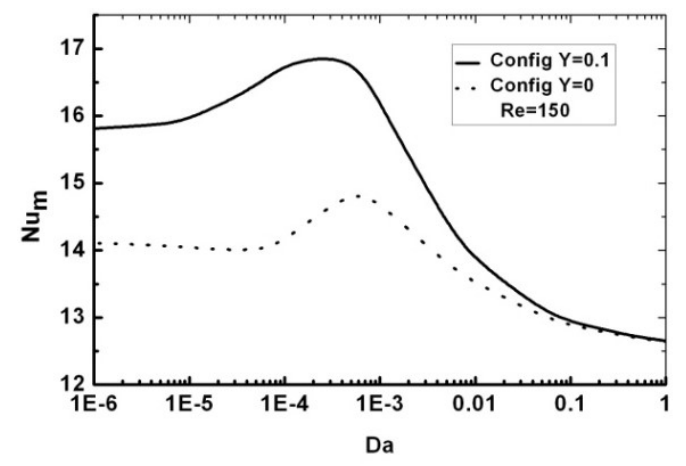

Figure 14. Comparison of the variations of the average Nusselt numbers of the two configurations with Darcy number. 
The overall pressure drop throughout the entire channel length is another important parameter to estimate in thermal engineering applications, since this pressure drop is the price that must be paid in return for the gain in heat transfer enhancement by inserting a porous substrate. The evolution of the average friction coefficient based on the Darcy number for the both configurations is shown in the Fig.15. A same values of the friction coefficien is noticed regardless of the value of Darcy number. When the Darcy number of the porous blocks decreases, the coefficient gradually increases and stabilizes for a Darcy number equal to $10^{-4}$.

This important results shows that the configuration $(\mathrm{Y} 1=0.1)$ is better than the configuration $(\mathrm{Y} 1=0)$, because its friction coefficient is less important at lower Darcy number.

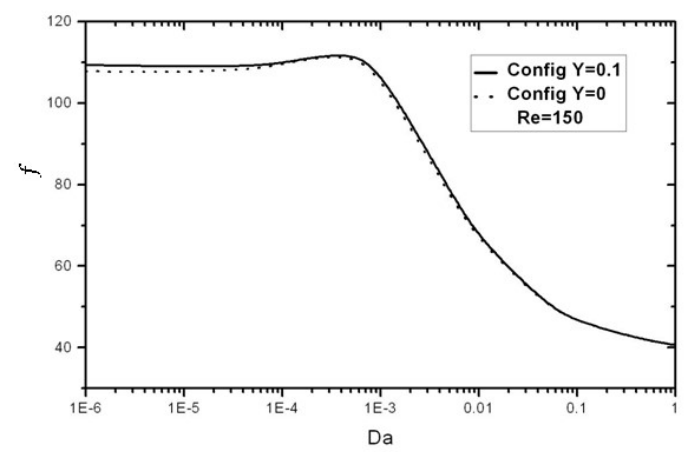

Figure 15. Comparison of the average friction coefficients of the two configurations with Darcy number.

\section{CONCLUSION}

This article has presented a numerical simulation of forced convection heat transfer enhancement of multiple porous blocks under localized heat flux in a horizontal parallel plate channel. Two different arrangements with four porous blocks are considered, in the first configuration, the blocks are fixed alternatively on the top and the bottom walls of the channel and in the second configuration the porous blocks are decollated away from the walls of the channel. The effect of the parameters such as the Darcy number, Reynolds number and the arrangement of the blocks on the flow pattern and heat transfer is analyzed.Throughout this investigation, some interesting results can be summarized as follows:

- The same value of the coefficient of friction is noticed for both configurations regardless of the Darcy number, a slight difference appears between them.

- With less quantity of porous material, the average Nusselt number is more important in the second configuration $\left(Y_{1}=0.1\right)$ around $12 \%$ relatively to the configuration $\left(Y_{1}=0\right)$ for Da lower than $10^{-3}$, following the better heat dissipation through the narrow gap that lies between the porous blocks and the wall.

- For application in electronic cooling equipment or solar collector system, there exists a critical value for Darcy number around $10^{-3}$ for which the heat transfer is desirable. Indeed, this value corresponds to that of metallic foams. Above this critical value, the heat transfer enhancement drops off.

In conclusion, we can say that our numerical simulation is limitated to the following cases :

- In laminar flow for Reynolds numbers varying between 100 and 500;

- For metal foams having a permeability corresponding to a Darcy number varying from 1 to $10^{-6}$;

- For a staggered metal foam blocks configuration, positioned at a distance from the channel walls between 0 and $0.1 \mathrm{H}$.

\section{NOMENCLATURE}

$\mathrm{C}_{\mathrm{p}} \quad$ Specific heat of air at constant pressure $\left(\mathrm{J} \mathrm{kg}^{-1} \mathrm{~K}^{-1}\right)$

$\mathrm{C}_{\mathrm{F}} \quad$ Inertial factor

Da Darcy number, $D a=\frac{K}{H^{2}}$ 
Journal of Thermal Engineering, Research Article, Vol. 7, No. 1, pp. 255-270, January, 2021

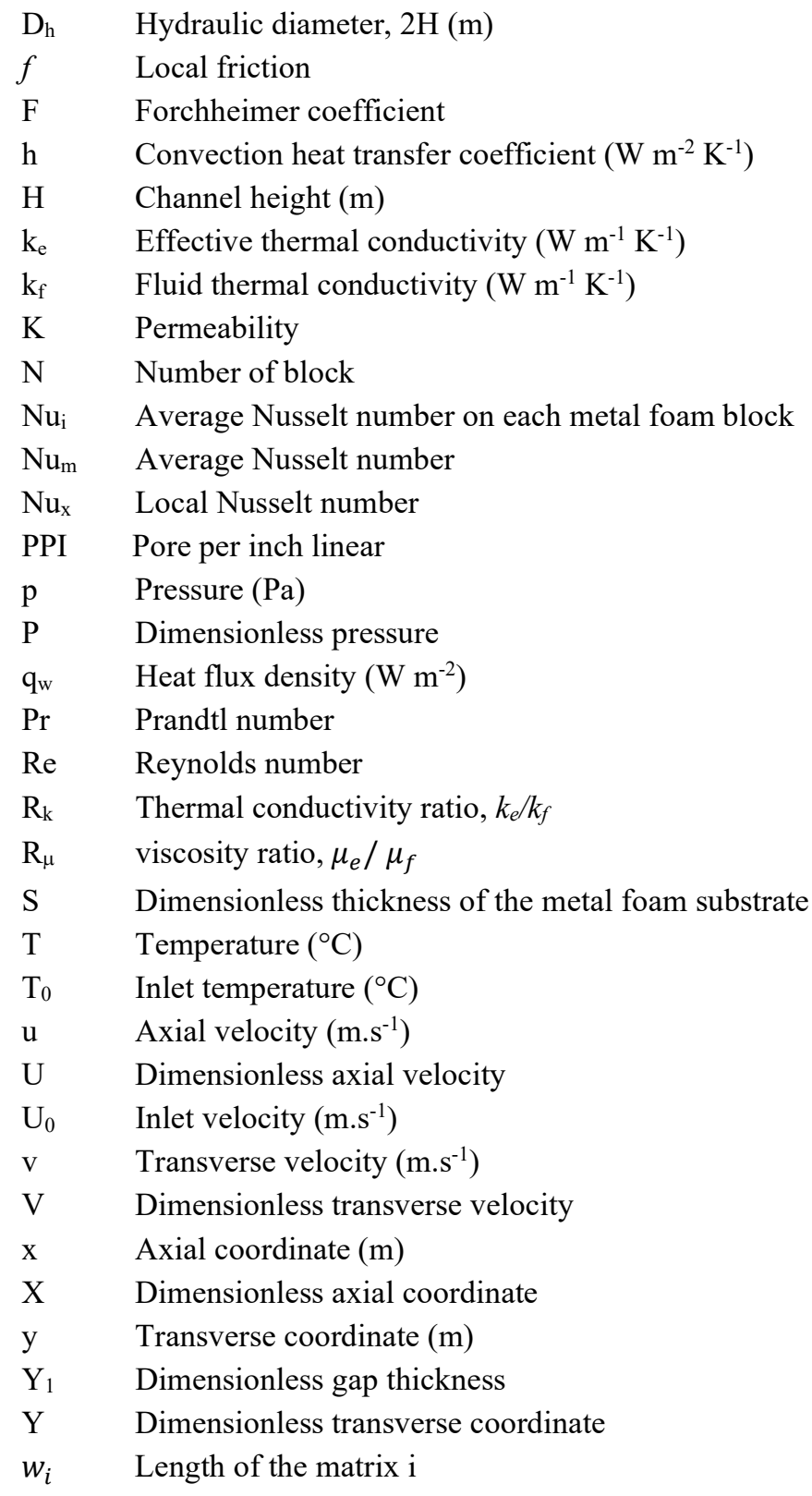

\section{Greek symbols}

$\alpha \quad$ Defined variable

$\varepsilon \quad$ Porosity (\%)

$\boldsymbol{\theta}$ Dimensionless temperature

$\boldsymbol{\theta}_{\mathrm{b}} \quad$ Dimensionless bulk temperature

$\boldsymbol{\theta}_{\mathrm{w}} \quad$ Dimensionless wall temperature

$\lambda \quad$ Binary variable

$\rho \quad$ Fluid density $\left(\mathrm{kg} . \mathrm{m}^{-3}\right)$

\section{Subscripts}

b Bulk

e Effective

f Fluid

m Average

0 Inlet

w Wall 


\section{REFERENCES}

[1] Jeng TM, Tzeng SC, Xu R. Experimental study of heat transfer characteristics in a 180-deg round turned channel with discrete aluminum-foam blocks. International Journal of Heat and Mass Transfer. 2014 Apr 1;71:133-41. doi:10.1016/j.ijheatmasstransfer.2013.11.035.

[2] Mancin S, Zilio C, Rossetto L, Cavallini A. Foam height effects on heat transfer performance of 20 ppi aluminum foams. Applied thermal engineering. 2012 Dec 31;49:55-60. doi:10.1016/j.applthermaleng.2011.05.015.

[3] Rong F, Zhang W, Shi B, Guo Z. Numerical study of heat transfer enhancement in a pipe filled with porous media by axisymmetric TLB model based on GPU. International Journal of Heat and Mass Transfer. 2014 Mar 1;70:1040-9. doi:10.1016/j.ijheatmasstransfer.2013.11.028.

[4] Qu ZG, Xu HJ, Tao WQ. Fully developed forced convective heat transfer in an annulus partially filled with metallic foams: an analytical solution. International Journal of Heat and Mass Transfer. 2012 Dec 1;55(25-26):7508-19. doi:10.1016/j.ijheatmasstransfer.2012.07.048.

[5] Chumpia A, Hooman K. Performance evaluation of tubular aluminum foam heat exchangers in single row arrays. Applied Thermal Engineering. 2015 May 25;83:121-30. doi:10.1016/j.applthermaleng.2015.03.015.

[6] Kamath PM, Balaji C, Venkateshan SP. Convection heat transfer from aluminium and copper foams in a vertical channel-An experimental study. International Journal of Thermal Sciences. 2013 Feb 1;64:10. doi:10.1016/j.ijthermalsci.2012.08.015.

[7] Abadi GB, Moon C, Kim KC. Experimental study on single-phase heat transfer and pressure drop of refrigerants in a plate heat exchanger with metal-foam-filled channels. Applied Thermal Engineering. 2016 Jun 5;102:423-31. doi:10.1016/j.applthermaleng.2016.03.099.

[8] Sung HJ, Kim SY, Hyun JM. Forced convection from an isolated heat source in a channel with porous medium. International journal of heat and fluid flow. 1995 Dec 1;16(6):527-35. doi:10.1016/0142727X(95)00032-L.

[9] Wang P, Liu DY, Xu C. Numerical study of heat transfer enhancement in the receiver tube of direct steam generation with parabolic trough by inserting metal foams. Applied energy. 2013 Feb 1;102:44960. doi:10.1016/j.apenergy.2012.07.026.

[10] Chen CC, Huang PC, Hwang HY. Enhanced forced convective cooling of heat sources by metal-foam porous layers. International Journal of Heat and Mass Transfer. 2013 Mar 1;58(1-2):356-73. doi:10.1016/j.ijheatmasstransfer.2012.11.041.

[11] Yang YT, Hwang ML. Numerical simulation of turbulent fluid flow and heat transfer characteristics in heat exchangers fitted with porous media. International Journal of Heat and Mass Transfer. 2009 Jun 1;52(13-14):2956-65. doi:10.1016/j.ijheatmasstransfer.2009.02.024.

[12] Jamal-Abad MT, Saedodin S, Aminy M. Experimental investigation on a solar parabolic trough collector for absorber tube filled with porous media. Renewable Energy. 2017 Jul 1;107:156-63. doi:10.1016/j.renene.2017.02.004.

[13] Arbak A, Bağcı Ö, Dukhan N. FLOW REGIMES IN COMMERCIAL METAL FOAM HAVING 10 PORES PER INCH. JOURNAL OF THERMAL ENGINEERING. 2016 Dec 1;2(6):1023-8.

[14] Jeng TM, Tzeng SC, Tang FZ. Fluid flow and heat transfer characteristics of the porous metallic heat sink with a conductive cylinder partially filled in a rectangular channel. International journal of heat and mass transfer. 2010 Sep 1;53(19-20):4216-27. doi:10.1016/j.ijheatmasstransfer.2010.05.044.

[15] Hamadouche A, Nebbali R, Benahmed H, Kouidri A, Bousri A. Experimental investigation of convective heat transfer in an open-cell aluminum foams. Experimental Thermal and Fluid Science. 2016 Feb 1;71:86-94. doi:10.1016/j.expthermflusci.2015.10.009.

[16] Dukhan N, Özdemir M, Kavurmacığlu L. Experimental fully-developed thermal convection for nondarcy water flow in metal foam. J. Therm. Eng.. 2016 Apr 1;2(2):677-82. doi:10.18186/JTE.46830.

[17] Patankar SV. Numerical heat transfer and fluid flow, Hemisphere Publ. Corp., New York. 1980;58. doi:10.1002/cite.330530323. 